Trinity University

Digital Commons @ Trinity

Chemistry Faculty Research

Chemistry Department

5-21-2010

\title{
Enhanced Oxygen Activation over Supported Bimetallic Au-Ni Catalysts
}

Bert D. Chandler

TrinityUniversity, bchandle@trinity.edu

Cormac G. Long

Trinity University

John D. Gilbertson

Trinity University

Christopher J. Pursell

TrinityUniversity, cpursell@trinity.edu

G. Vijayaraghavan

See next page for additional authors

Follow this and additional works at: https://digitalcommons.trinity.edu/chem_faculty

Part of the Chemistry Commons

\section{Repository Citation}

Chandler, B. D., Long, C. G., Gilbertson, J. D., Pursell, C. J., Vijayaraghavan, G., \& Stevenson, K. J. (2010). Enhanced oxygen activation over supported bimetallic Au-Ni catalysts. Journal of Physical Chemistry C, 114(26), 11498-11508

This Article is brought to you for free and open access by the Chemistry Department at Digital Commons @ Trinity. It has been accepted for inclusion in Chemistry Faculty Research by an authorized administrator of Digital Commons @ Trinity. For more information, please contact 
Authors

Bert D. Chandler, Cormac G. Long, John D. Gilbertson, Christopher J. Pursell, G. Vijayaraghavan, and K. J.

Stevenson

This article is available at Digital Commons @ Trinity: https://digitalcommons.trinity.edu/chem_faculty/9 


\title{
Enhanced Oxygen Activation over Supported Bimetallic Au-Ni Catalysts
}

\author{
Bert D. Chandler, ${ }^{*},{ }^{\dagger}$ Cormac G. Long, ${ }^{\dagger}$ John D. Gilbertson, ${ }^{\dagger}, *$ Christopher J. Pursell, ${ }^{\dagger}$ \\ Ganesh Vijayaraghavan, ${ }^{\S}$ and Keith J. Stevenson ${ }^{\S}$ \\ Department of Chemistry, Trinity University, San Antonio, Texas 78212-7200, and Department of Chemistry, \\ University of Texas at Austin, 1 University Station A5300, Austin, Texas 78712-0165
}

Received: March 1, 2010; Revised Manuscript Received: May 21, 2010

\begin{abstract}
New bimetallic $\mathrm{Ni}-\mathrm{Au}$ supported nanoparticle catalysts were prepared by using dendrimer templated nanoparticles. Amine-terminated generation 5 polyamidoamine (PAMAM) dendrimers were anchored to a commercial silica with a siloxane linked anhydride. The dendrimer was then alkylated and used to template $\mathrm{Ni}-\mathrm{Au}$ nanoparticles, which were subsequently extracted into organic solution as thiol monolayer protected clusters (MPCs). Transmission electron microscopy (TEM) and energy dispersive spectroscopy (EDS) indicated bimetallic nanoparticles of about $2 \mathrm{~nm}$ in size. Nanoparticles were deposited onto P-25 $\mathrm{TiO}_{2}$, and the capping thiol ligands were removed under flowing $\mathrm{H}_{2}$. DRIFTS infrared spectra of adsorbed $\mathrm{CO}$ showed only Au on the catalyst surface; no bands attributable to Ni or NiO were observed. Density functional theory (DFT) calculations showed that $\mathrm{Au}$ is substantially more stable than Ni on the surface of model slabs. DFT calculations also indicated that the incorporation of $\mathrm{Ni}$ into Au slabs results in stronger adsorption of $\mathrm{O}$ and $\mathrm{CO}$ on $\mathrm{Au}$ surfaces. Catalysts were evaluated with low-temperature $\mathrm{CO}$ oxidation. Kinetics studies indicated a substantial modification of Au catalysis through $\mathrm{Ni}$ incorporation. Apparent activation energies decreased by more than $50 \%$ and $\mathrm{O}_{2}$ reaction orders increased from 0.2 to 0.9 . These results are placed in the context of the available literature regarding support effects for Au catalysts. The observed changes to Au chemistry in the current work are substantially larger than previous reports have attributed to support effects. A Michaelis-Menten (enzyme) treatment of the kinetics data indicated that the $\mathrm{O}_{2}$ reactivity constant increased by a factor of 40 for catalysts with high $\mathrm{Ni}$ content. This was in good qualitative agreement with the DFT calculations. At the same time, the introduction of Ni reduced the relative number of catalytically active sites.
\end{abstract}

\section{Introduction}

The high activity of supported gold catalysts for catalyzing $\mathrm{CO}$ oxidation at subambient temperatures has been well documented over the past 20 years. ${ }^{1,2}$ The last several years have seen intense interest in applying Au catalysts to a variety of new reactions, particularly the Water-Gas Shift reaction and low temperature oxidation and epoxidation reactions that use $\mathrm{O}_{2}$ as the terminal oxidant. ${ }^{3,4}$ In spite of the substantial research activity in gold-catalyzed oxidation reactions, the origins of the catalytic activity are still not well understood. Important issues under investigation include oxygen binding and activation, the importance of the support in affecting catalytic activity, the $\mathrm{Au}$ oxidation state necessary for high activity, the sensitivity to water or surface hydroxyl groups, and the strong dependence on particle size and morphology. ${ }^{2}$

The binding and activation of molecular oxygen is generally considered to be the key catalytic step in highly active $\mathrm{Au}$ oxidation catalysts. ${ }^{2}$ For $\mathrm{CO}$ oxidation, the literature provides a general consensus that $\mathrm{O}_{2}$ activation occurs on only a fraction of the surface $\mathrm{Au}$ atoms, probably predominately corner or edge sites. $^{2}$ A number of models propose that $\mathrm{O}_{2}$ is activated at or near the metal-support interface, ${ }^{1,5}$ which may partially account for the unusually high sensitivity of Au catalysts to the support material and preparation method. Both computational studies

\footnotetext{
* To whom correspondence should be addressed. E-mail: bert.chandler@ trinity.edu. Phone: (210) 999-7557. Fax: (210) 999-7569.

$\uparrow$ Trinity University.

* Current address: Department of Chemistry, Western Washington University, 516 High St., Bellingham, Washington 98225-9150.

$\S$ University of Texas at Austin.
}

and studies on model systems under UHV conditions have shed considerable light onto the unique activity of Au catalysts, ${ }^{6-8}$ however, different models suggest a variety of answers to the key issues. ${ }^{9}$ Further, a recent review highlights the difficulties of preparing active supported nanoparticle (NP) catalysts, and the challenges of comparing them to model systems (computational and UHV). ${ }^{2}$

Whether they arise from various support effects or preparation methods, the changes to catalytic activity have largely been phenomenological in origin; in other words, catalyst-to-catalyst differences have been discovered, reported, and in some cases rationalized. There have been far fewer attempts to control the catalytic chemistry of Au based on some sort of catalyst design principles. One potential method for intentionally affecting catalytic activity is to incorporate other metals into Au NPs. $\mathrm{Au}$ has long been used as a diluent for "more reactive" metals (e.g., Pt and Pd). ${ }^{10}$ For example, dilution of Pd with Au generates materials with exceptional catalytic activity and selectivity in the oxidation of ethylene to vinyl acetate. ${ }^{11}$ However, there are exceedingly few studies of bimetallic Au catalysts where Au is the primary active component. Recent studies have examined $\mathrm{Au}-\mathrm{Cu}^{12,13}$ and $\mathrm{Au}-\mathrm{Ag}^{14}$ catalysts for $\mathrm{CO}$ and benzyl alcohol oxidation, ${ }^{15}$ and Louis' group has reported that trace amounts of Pd enhance the reactivity of Au. ${ }^{16}$ Beyond these investigations, we are unaware of any systematic investigation of incorporating heterometals into Au NP catalysts.

One of the primary reasons for this dearth of studies into bimetallic Au-based catalysts is the difficulty in preparing them. In general, bulk alloys between Au and other transition metals are not thermodynamically stable at ambient temperatures (Pd, 
$\mathrm{Cu}$, and $\mathrm{Ag}$ are notable exceptions). ${ }^{17}$ Therefore, traditional catalyst preparation methods generally lead to supported catalysts composed of mixtures of monometallic NPs rather than bimetallic nanometer scale alloys. We have previously shown, however, that it is possible to use solution NP preparation techniques to prepare heterogeneous catalysts with compositions inside bulk miscibility gaps, ${ }^{18}$ and that it is possible to exert substantial control over catalyst activity by adjusting bimetallic metal ratios. ${ }^{19}$ Herein, we report on our efforts to develop methods for tuning the catalytic activity of Au NP catalysts by controllably incorporating heterometals into supported Au NPs. The focus of this study was to prepare a series of $\mathrm{Ni}-\mathrm{Au}$ catalysts and perform reaction kinetics studies in order to understand how $\mathrm{Ni}$ incorporation affects the catalysis. To our knowledge, this is the first attempt to tune Au catalysts in such a manner.

The $\mathrm{Ni}-\mathrm{Au}$ system has long been of interest, as incorporating $\mathrm{Au}$ into Ni-based steam reforming catalysts improves sulfur tolerance ${ }^{20}$ however, there are few studies examining the effects of $\mathrm{Ni}$ on catalysis by Au. Of note is Lahr and Ceyer's recent UHV study showing enhanced low-temperature reactivity between preadsorbed $\mathrm{O}$ atoms and $\mathrm{CO}$ over $\mathrm{Au} / \mathrm{Ni}(111)$ surface alloys. ${ }^{21,22}$ This discovery has yet to be translated into the preparation of highly active supported catalysts. The bulk phase diagram shows $\mathrm{Ni}$ and $\mathrm{Au}$ are immiscible at temperatures below $500 \mathrm{~K},{ }^{23}$ so traditional catalyst preparation methods lead to mixtures of monometallic NPs rather than bimetallic nanometer scale alloys. ${ }^{24,25}$ Despite this phase segregation, there are reports that $\mathrm{Ni}-\mathrm{Au}$ catalysts show improved performance for hydrodechlorination ${ }^{25}$ and that $\mathrm{NiO}$ improves performance for $\mathrm{CO}$ oxidation ${ }^{26}$ and allylbenzene isomerization. ${ }^{27}$

Advances in solution phase NP preparation techniques, however, have made it possible to prepare metastable nanometer scale alloys with compositions throughout bulk miscibility gaps. ${ }^{18,28,29}$ This, in turn, offers potential synthetic routes to new catalysts with unique activities and selectivities. Several groups, including our own, have recently reported solution syntheses to $\mathrm{Ni}-\mathrm{Au}$ NPs. ${ }^{26,30,31}$ Notably, one study showed that $\mathrm{Ni}-\mathrm{Au}$ NPs are appropriate precursors to heterogeneous $\mathrm{Au} / \mathrm{NiO} / \mathrm{SiO}_{2}$ catalysts. ${ }^{26}$ On the basis of these results, and particularly our previous experience preparing $\mathrm{Ni}-\mathrm{Au} \mathrm{NPs}$ in solution, we therefore set out to tune Au catalysts by incorporating varying amounts of Ni into the NP syntheses.

Beyond developing new catalyst preparation techniques, quantitative kinetics are important measures for determining how heterometals might affect $\mathrm{Au}$ catalysts. It is therefore of fundamental and practical interest and importance to gain deeper insight into Au-based oxidation reactions, and to develop methods for improving their performance as catalysts for chemical transformations. Surface science studies have contributed greatly to our understanding of reaction mechanisms over $\mathrm{Au},{ }^{32}$ but studies of oxygen activation on bench scale catalysts have been scarce. ${ }^{33}$ Oxygen binding by Au single crystals and NPs is weak (less than $10 \mathrm{~kJ} / \mathrm{mol}$ ), ${ }^{33}$ and direct measurements of the $\mathrm{O}_{2}$ adsorption equilibrium constant have been unsuccessful. However, we recently employed a Michaelis-Menten technique that allows for the extraction of a kinetic $\mathrm{O}_{2}$ binding constant during $\mathrm{CO}$ oxidation catalysis. ${ }^{33}$ This study showed $\mathrm{O}_{2}$ binding to be quite consistent over two $\mathrm{Au} / \mathrm{TiO}_{2}$ catalysts prepared by very different means. In the current work, we extend these studies to the newly prepared $\mathrm{Ni}-\mathrm{Au}$ catalysts to evaluate the degree to which $\mathrm{Ni}$ incorporation affects catalysis by $\mathrm{Au}$ and to provide insight into how this modification might occur.

\section{Experimental Section}

Materials and Reagents. Davicat SI 1403 (Grace Davison) silica was sieved to $40-60$ mesh and calcined at $500{ }^{\circ} \mathrm{C}$ overnight. Amine-terminated generation 5 polyamidoamine (PAMAM) dendrimer was purchased from Dendritech. $\mathrm{HAuCl}_{4}$ (99\%, Alfa), $\mathrm{NiCl}_{2} \cdot 6 \mathrm{H}_{2} \mathrm{O}$ (99\%, Alfa), decanethiol (98\% Aldrich), and 1,2-epoxydodecane (98\% Aldrich) were used as received. 3-(Triethoxysilyl)propylsuccinic anhydride, 95\%, was purchased from Gelest and used as received. Reagent grade toluene, methanol, ethanol, and DMF (Fischer) were dried under molecular sieves (Davison, grade 564, $3 \AA$ ) and otherwise used as received. Water was purified to a resistivity of 17-18 $\mathrm{M} \Omega \cdot \mathrm{cm}$ with a Barnstead Nanopure system. P25 Titania (Aerolyst 7711) was generously provided by Degussa Corporation. The World Gold Council test (nominally $1 \% \mathrm{Au} / \mathrm{TiO}_{2}$ ) catalyst was purchased from the World Gold Council.

Characterization. Solution UV-visible absorbance spectra were collected on a Jasco V-530 spectrometer with quartz cells. Transmission electron microscopy (TEM) analysis of the NPs was performed with a JEOL $2010 \mathrm{~F}$ instrument operating at 200 $\mathrm{kV}$. NPs suspended in hexane were drop cast onto a 150 mesh $\mathrm{Cu}$ TEM grid covered with a thin amorphous carbon film. Image analysis was performed with DigitalMicrograph 3.6.1 (Gatan) software. Elemental analyses were performed by Desert Analytics (Tucson, AZ). DRIFT spectra were collected on a ThermoNicolet Nexus 470 FT-IR, using a Thermo-Electron environmental cell accessory.

Functionalization of 40-60 Silica. A $25 \mathrm{~mL}$ sample of toluene was added to a $50 \mathrm{~mL}$ Erlenmeyer flask containing $2 \mathrm{~g}$ of freshly calcined 40-60 silica. Then $2 \mathrm{~mL}$ of 3-(triethoxysilyl)propylsuccinic anhydride was added to the slurry and the flask was sealed and allowed to stir on a shaker at $60 \mathrm{rpm}$ overnight. This slurry was then filtered under vacuum, rinsed with $50 \mathrm{~mL}$ of EtOH $(2 \times 25 \mathrm{~mL})$, and allowed to dry on the filter.

Dendrimer Anchoring and Alkylation. A $30 \mathrm{mg}$ sample of G5- $\mathrm{NH}_{2}$ PAMAM dendrimer (1.04 $\left.\mu \mathrm{mol}\right)$ was dissolved with sonication in a minimal amount of EtOH $(\sim 3 \mathrm{~mL})$ in a $20 \mathrm{~mL}$ vial. To this vial was added DMF until just before the solution became cloudy, typically $\sim 10 \mathrm{~mL}$. The solution from the vial was then added to a $50 \mathrm{~mL}$ Erlenmeyer flask containing anhydride functionalized silica $(\sim 2 \mathrm{~g})$ collected from the above procedure. The flask was sealed, placed in a shaker at $60 \mathrm{rpm}$, and heated at $45{ }^{\circ} \mathrm{C}$ for $24 \mathrm{~h}$. The anchored amine-terminated dendrimer is denoted $\mathrm{SiO}_{2}-\mathrm{G}_{5} \mathrm{NH}_{2}$.

To the above slurry was added $1 \mathrm{~g}(5.4 \mathrm{mmol})$ of 1,2 epoxydodecane. The solution was shaken at $50 \mathrm{rpm}$ in a sealed vessel at $45^{\circ} \mathrm{C}$ for $48 \mathrm{~h}$. After reaction, the solid was filtered via vacuum, rinsed with $\mathrm{EtOH}$, and allowed to dry in a vacuum oven at $40{ }^{\circ} \mathrm{C}$ overnight. The anchored, alkylated amineterminated dendrimer is denoted $\mathrm{SiO}_{2}-\mathrm{G}_{5} \mathrm{C}_{12}$.

Preparation of Au DENs. A $300 \mathrm{mg}$ sample of the solid obtained from above (with an average loading of $0.52 \mathrm{nmol}$ of dendrimer/mg of silica) was placed in a $25 \mathrm{~mL}$ vial containing $10 \mathrm{~mL}$ of toluene and allowed to sit for 30 min producing a $15.6 \mu \mathrm{M}$ slurry. To that mixture was added $7.8 \mathrm{mg}$ of $\mathrm{HAuCl}_{4}$ (23 $\mu \mathrm{mol}$ ) in $5.3 \mathrm{~mL}$ of EtOH to give a 147:1 Au:dendrimer molar ratio. The vial was sealed and placed on a shaker at 60 $\mathrm{rpm}$ for $1 \mathrm{~h}$ and then filtered, rinsed with $10 \mathrm{~mL}(3 \times)$ of toluene, and redispersed in $20 \mathrm{~mL}$ of fresh toluene in a vial containing a stir bar. Then $2.0 \mathrm{~mL}$ of freshly prepared $50 \mathrm{mM} \mathrm{NaBH}_{4}$ in $\mathrm{MeOH}$ was added to the stirring yellow slurry, instantly changing the color from yellow to brown. 
Preparation of $\mathrm{Ni}-\mathrm{Au}$ DENs. A $300 \mathrm{mg}$ sample of the anchored/alkylated dendrimer silica with an average loading of $0.52 \mathrm{nmol}$ of dendrimer/mg of silica was placed in a $25 \mathrm{~mL}$ vial containing $10 \mathrm{~mL}$ of toluene and allowed to sit for $30 \mathrm{~min}$ producing a $15.6 \mu \mathrm{M}$ slurry. To that mixture were added $2 \mathrm{mg}$ $(8.6 \mu \mathrm{mol})$ of $\mathrm{NiCl}_{2} \cdot 6 \mathrm{H}_{2} \mathrm{O}$ in $1 \mathrm{~mL}$ of EtOH and $6.3 \mathrm{mg}(18.5$ $\mu \mathrm{mol})$ of $\mathrm{HAuCl}_{4}$ in $2 \mathrm{~mL}$ of $\mathrm{EtOH}$ to give a $147: 1$ metal: dendrimer ratio. Au:Ni ratios were adjusted to 2, 1.5, 1, 0.5, and 0.3 . The vial was sealed and placed on a shaker at $60 \mathrm{rpm}$ for $1 \mathrm{~h}$ and then filtered, rinsed with $10 \mathrm{~mL}(3 \times)$ of toluene, and redispersed in $20 \mathrm{~mL}$ of fresh toluene in a vial containing a stir bar. The vial was sealed with a septum and deoxygenated by sparging Ar for $30 \mathrm{~min}$ with stirring. Then $2.0 \mathrm{~mL}$ of freshly prepared and deoxygenated $50 \mathrm{mM} \mathrm{NaBH}_{4}$ in $\mathrm{MeOH}$ was added to the stirring yellow/green slurry under flowing Ar, instantly changing the color of the solid from yellow/green to brown.

Extraction and Purification of Ni-Au MPCs. A deoxygenated solution of $3.0 \mathrm{~mL}$ of decanethiol in $5 \mathrm{~mL}$ of toluene was instantly added under flowing Ar to the above mixture containing the anchored $\mathrm{Ni}-\mathrm{Au} \mathrm{DENs}$ with vigorous stirring (magnetic stir bar with stirrer set on high). The solution turns from colorless to brown instantly, but was allowed to stir for at least $30 \mathrm{~min}$, yielding a brown solution of extracted $\mathrm{Ni}-\mathrm{Au}$ MPCs. The toluene solution containing the MPC product was filtered and purified by first concentrating the solution to $1 \mathrm{~mL}$ on a rotary evaporator and then adding $15 \mathrm{~mL}$ of ethanol to precipitate the MPCs. Centrifugation resulted in separation of the MPCs from excess free $n$-alkanethiol and other impurities. The MPCs were washed and centrifuged twice with ethanol to ensure complete purification.

MPC Deposition and Thiol Removal (Catalyst Activation). The purified $\mathrm{Au}$ MPCs were deposited onto $\mathrm{TiO}_{2}$ by adapting a literature method. ${ }^{34}$ Briefly, sufficient Au MPCs to produce a 0.2 wt $\%$ Au loading were dissolved in a minimum amount of methylene chloride and added to a vigorously stirring suspension of $100 \mathrm{mg}$ of $\mathrm{TiO}_{2}$ in $5 \mathrm{~mL}$ of methylene chloride. The suspension was stirred until the methylene chloride was no longer colored (ca. $5 \mathrm{~min}$ ). The $\mathrm{TiO}_{2}$ was then rinsed 3 times with $5 \mathrm{~mL}$ of methylene chloride and dried in air for $1 \mathrm{~h}$ at 393 $\mathrm{K}$. The $\mathrm{MPC} / \mathrm{TiO}_{2}$ samples (typically $100 \mathrm{mg}$ ) were placed in a tube furnace and treated under flowing $\mathrm{H}_{2} / \mathrm{N}_{2}$ (50/50 mixture, $20 \mathrm{~mL} / \mathrm{min}$ ) at $563 \mathrm{~K}$ for $16 \mathrm{~h}$. The initial ramp in temperature from 298 to $563 \mathrm{~K}$ was $2.2 \mathrm{deg} / \mathrm{min}$ for $2 \mathrm{~h}$.

Elemental Analysis via Atomic Absorption Spectroscopy. Gold and nickel elemental concentrations were determined with a Varian SpectrAA 220FS, using an acetylene/air flame and a previously described protocol. ${ }^{30,35}$ Briefly, solid samples were placed in an Erlenmeyer flask. Freshly prepared aqua regia (3 $\mathrm{mL}$ ) was then added to the sample and allowed to digest at room temperature for $30 \mathrm{~min}$. The sample was then heated slowly to $60{ }^{\circ} \mathrm{C}$ for $2 \mathrm{~h}$. The sample was transferred to a volumetric flask $(10 \mathrm{~mL})$ and $\mathrm{NH}_{4} \mathrm{OH}$ was added dropwise until teh sample was neutralized. The sample was then diluted to the mark with nanopure water and subsequently analyzed. Experimental errors for the method and the spectrometer are typically less than $5 \%$.

X-ray Photoelectron Spectroscopy. X-ray photoelectron spectroscopy (XPS) spectra were collected with a Kratos AXIS Ultra DLD photoelectron spectrophotometer, using a monochromatic Aluminum X-ray source at $160 \mathrm{~W}$. Each highresolution analysis had a pass energy of $60 \mathrm{eV}$ that was lowered at steps of $100 \mathrm{meV}$ and the dwell time of $1000 \mathrm{~ms}$. To exclude any effects on the values of binding energies due to charging of the sample during the XPS analysis, all data were corrected by using the AXIS charge neutralization system, which provides charge compensation on all types of conductive materials and is particularly important when using a monochromatic X-ray source.

Infrared Spectroscopy of Adsorbed CO. FTIR spectra were collected with a Thermo-Nicolet Nexus 470 spectrometer equipped with a DTGS detector with a resolution of $16 \mathrm{~cm}^{-1}$. A powder sample was placed in an in situ DRIFT cell (ThermoSpectraTech), sealed, and treated under flowing $\mathrm{H}_{2}$ at $423 \mathrm{~K}$ for $30 \mathrm{~min}$. The cell was then flushed with $\mathrm{He}$ at $423 \mathrm{~K}$ for 30 min and cooled to $293 \mathrm{~K}$ under flowing $\mathrm{He}(5 \mathrm{~min})$, then a background spectrum of the sample was collected (32 scans). Flowing $\mathrm{CO}(5 \%$ in $\mathrm{He})$ was then introduced to the sample chamber for $5 \mathrm{~min}$ and a spectrum was recorded. Reference spectra of gas-phase $\mathrm{CO}$ and $\mathrm{CO}_{2}$ were subtracted from sample spectra with the Omnic software, yielding the spectrum of $\mathrm{CO}$ adsorbed on the catalyst.

CO Oxidation Catalysis. The CO oxidation reactor system consisted of a custom built laboratory scale single pass plugflow microreactor, as described previously. ${ }^{33}$ Supported catalyst samples were diluted 1250:1 with 400 mesh silicon carbide (Aldrich) and placed in the microreactor. All reactions were performed at ambient pressure with $1 \% \mathrm{CO}$ in the feed, which was maintained with Porter mass flow controllers. The diluted catalyst mass, nominally $250 \mathrm{mg}$, and gas flows, typically near $25 \mathrm{~mL} / \mathrm{min}$, were adjusted to maintain differential reactor conditions and conversions studied were always between $1 \%$ and $2 \%$. Changes in $\mathrm{CO}$ oxidation activity were measured as a function of temperature as well as $\mathrm{CO}$ and $\mathrm{O}_{2}$ feed concentration. All activities were determined by averaging steady state conversion data for approximately $2 \mathrm{~h}$, usually between 1 and $3 \mathrm{~h}$ after introducing $\mathrm{CO}$ to the activated catalyst. Each activity measurement was performed with a fresh catalyst sample.

Computational Methods. All DFT calculations were performed at the Center for Atomic Scale Materials Design at the Danish Technical University in Copenhagen, Denmark. Metal slab, adsorption, and gas-phase energies were calculated by using the plane wave DFT code DACAPO ${ }^{36}$ Kohn-Sham one electron valence states were expanded in a basis of plane waves with kinetic energies up to $30 \mathrm{Ry}$. Vanderbilt nonlocal ultrasoft pseudopotentials were used to describe the core electrons. The exchange correlation (xc)-energy was described employing the RPBE generalized gradient correction self-consistency. ${ }^{36}$

For all surfaces, a $6 \times 6 \times 1$ Monkhorst-Pack k-point sampling in the irreducible Brilluoin zone was used. The occupation of the one electron states was calculated at a temperature of $k_{\mathrm{b}} T$ $=0.1 \mathrm{eV}$, and all energies were extrapolated to $T=0 \mathrm{~K}$. Lattice constants have been determined by separate calculations on the bulk metals. The $(111)$ surfaces were modeled with $(2 \times 2)$ surface unit cells with a slab thickness of four layers. Neighboring slabs were separated by more than $10 \AA$ of vacuum. The bottom-most layer was fixed to the Au lattice and the top three layers were allowed to relax.

Adsorption calculations were preformed fixing all metal atoms, allowing only the adsorbate to relax. Atomic oxygen adsorption energies were calculated relative to the $\mathrm{O}_{2}$ energy from $\mathrm{H}_{2} \mathrm{O}$ splitting by using the experimental reaction energy and that for $\mathrm{H}_{2}$ and $\mathrm{H}_{2} \mathrm{O}$ in the gas phase. ${ }^{37}$ This avoids difficulties associated with the DFT treatment of the triplet state of gas-phase $\mathrm{O}_{2}{ }^{38} \mathrm{CO}$ adsorption energies were calculated relative to gas-phase $\mathrm{CO}$.

\section{Results and Discussion}

We set out to tune the catalytic properties of $\mathrm{Au} / \mathrm{TiO}_{2}$ catalysts by incorporating $\mathrm{Ni}$ into solution phase Au NPs. NPs were 
TABLE 1: Catalyst Composition Data

\begin{tabular}{|c|c|c|c|c|c|c|c|}
\hline $\begin{array}{l}\text { synthesis } \mathrm{Au}: \mathrm{Ni} \\
\text { mass ratio }\end{array}$ & $\begin{array}{l}\text { measured } \\
\text { wt } \% \mathrm{Ni}\end{array}$ & $\begin{array}{l}\text { measured } \\
\text { wt } \% \mathrm{Au}\end{array}$ & $\begin{array}{c}\text { total } \\
\text { wt } \% \text { metal }\end{array}$ & $\begin{array}{c}\text { measured } \mathrm{Au}: \mathrm{Ni} \\
\text { mass ratio }\end{array}$ & $\operatorname{mol} \% \mathrm{Ni}$ & $\operatorname{mol} \% \mathrm{Au}$ & $\begin{array}{c}\text { catalyst } \\
\text { designation }\end{array}$ \\
\hline 1 & 0.062 & 0.078 & 0.14 & 1.3 & $73 \%$ & $27 \%$ & $\mathrm{AuNi}_{3}$ \\
\hline 2 & 0.043 & 0.087 & 0.13 & 2.0 & $62 \%$ & $38 \%$ & $\mathrm{AuNi}_{2}$ \\
\hline 4 & 0.045 & 0.175 & 0.22 & 3.9 & $46 \%$ & $54 \%$ & $\mathrm{Au}_{1} \mathrm{Ni}_{1}$ \\
\hline 5 & 0.040 & 0.190 & 0.23 & 4.8 & $41 \%$ & $59 \%$ & $\mathrm{Au}_{2} \mathrm{Ni}_{3}$ \\
\hline 6 & 0.040 & 0.249 & 0.29 & 6.2 & $35 \%$ & $65 \%$ & $\mathrm{Au}_{2} \mathrm{Ni}$ \\
\hline
\end{tabular}

prepared by adapting our previously reported synthetic protocols for preparing Ni@Au core-shell NPs. ${ }^{30}$ Briefly, the surface of a commercial high surface area, high pore volume silica was functionalized with 3-(triethoxysilyl)propylsuccinic anhydride. Amine-terminated generation 5 PAMAM dendrimers were used to open the surface anhydride, thus anchoring the dendrimers to the silica. The anchored dendrimers were subsequently alkylated with 1,2-epoxydodecane to yield a hydrophobic dendrimer surface. $\mathrm{Ni}^{\mathrm{II}}$ and $\mathrm{Au}^{\mathrm{III}}$ were introduced to the dendrimer interior by dissolving the precursor salts in ethanol and adding a small aliquot of the ethanol solution to the anchored, alkylated dendrimer suspended in toluene. After metal uptake was complete, the salts were reduced with sodium borohydride in toluene with use of standard Schlenk techniques. In the absence of water and air, NPs were then extracted from the dendrimer interior with decanethiol in toluene or methylene
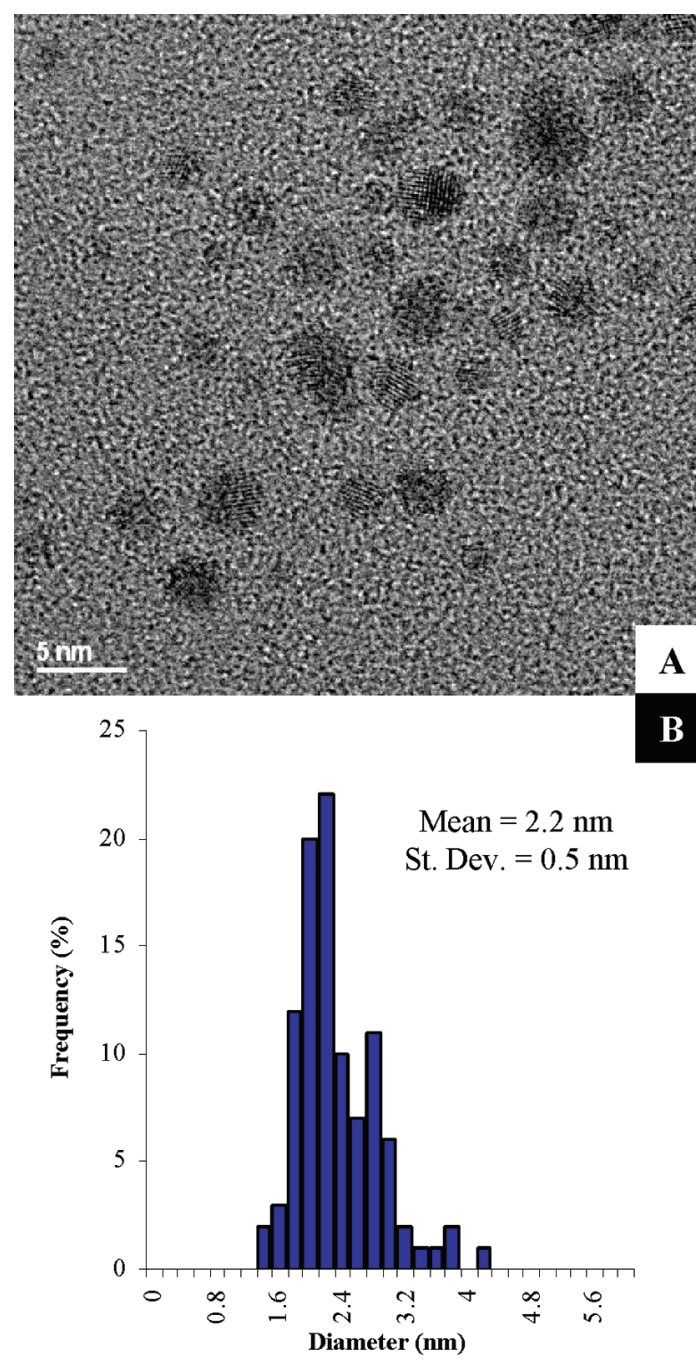

Figure 1. (A) Representative TEM image for $\mathrm{Au}_{1} \mathrm{Ni}_{1}$ nanoparticles. (B) Size histogram of $\mathrm{Au}_{1} \mathrm{Ni}_{1}$ nanoparticles (105 particles counted). chloride, yielding monolayer protected clusters (MPCs). The details of these synthetic protocols and characterization information have already been reported for monometallic Au NPs and $\mathrm{Ni@Au} \mathrm{core-shell} \mathrm{NPs.}{ }^{30,39}$

Catalyst Synthesis and Characterization. The total metal: dendrimer ratio was held constant at 147:1 for all syntheses; only the Au:Ni ratios were adjusted to yield catalysts with $\mathrm{Au}$ : $\mathrm{Ni}$ molar ratios ranging from pure $\mathrm{Au}$ to $75 \% \mathrm{Ni}$ (mass ratios from 6 to 1). Catalyst designations ( $\mathrm{Au}, \mathrm{Au}_{2} \mathrm{Ni}, \mathrm{Au}_{3} \mathrm{Ni}_{2}, \mathrm{Au}_{1} \mathrm{Ni}_{1}$, $\mathrm{AuNi}_{2}, \mathrm{AuNi}_{3}$ ) are based on the atomic ratios of $\mathrm{Au}$ and $\mathrm{Ni}$. A representative TEM micrograph and particle size distribution are shown in Figure 1; single particle EDS spectra confirmed the presence of both $\mathrm{Ni}$ and $\mathrm{Au}$ in individual NPs. ${ }^{30}$ Preliminary TEM studies indicate the presence of a range of particle compositions, as Crooks' group has reported for other dendrimer templated bimetallic nanoparticle systems. ${ }^{40}$

The MPCs were deposited onto $\mathrm{P}-25 \mathrm{TiO}_{2}$ via spontaneous adsorption from $\mathrm{CH}_{2} \mathrm{Cl}_{2}$, and activated by heating to $300{ }^{\circ} \mathrm{C}$ under flowing $\mathrm{H}_{2} / \mathrm{N}_{2}$ for $16 \mathrm{~h}$ (see details in the Experimental Section). This pretreatment has been previously shown to produce highly active Au catalysts from Au MPCs. ${ }^{33,34}$ Catalyst compositions after pretreatment were confirmed by atomic adsorption spectroscopy (AAS). Table 1 shows the total metal loadings were near $0.2 \mathrm{wt} \%$ and elemental ratios were in good agreement with the metal ratios used in the synthesis. Additionally, the $\mathrm{Au}_{1} \mathrm{Ni}_{1}$ catalyst synthesis was repeated three times to evaluate reproducibility (see the Supporting Information). For all three preparations, the bulk catalyst composition was within $5 \%$ of the mole ratio set during NP synthesis.

Catalyst surface composition was evaluated by using DRIFT spectroscopy of adsorbed CO. The DRIFTS spectrum of CO on the $\mathrm{Au}_{1} \mathrm{Ni}_{1}$ catalyst, shown in Figure 2, contains a single peak at $2105 \mathrm{~cm}^{-1}$. A similar spectrum was collected for a $1 \%$ $\mathrm{AuNi}_{3} / \mathrm{TiO}_{2}$ catalyst (see the Supporting Information). This peak is consistent with $\mathrm{CO}$ adsorbed on surface Au atoms. ${ }^{33}$ Notably,

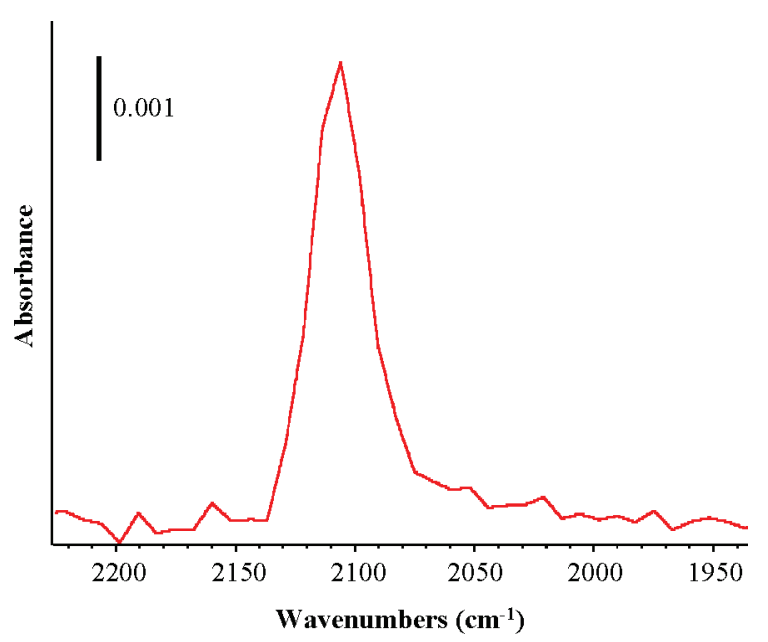

Figure 2. DRIFTS IR spectrum of $\mathrm{CO}$ adsorbed on an activated $\mathrm{Au}_{1} \mathrm{Ni}_{1}$ catalyst at room temperature. 

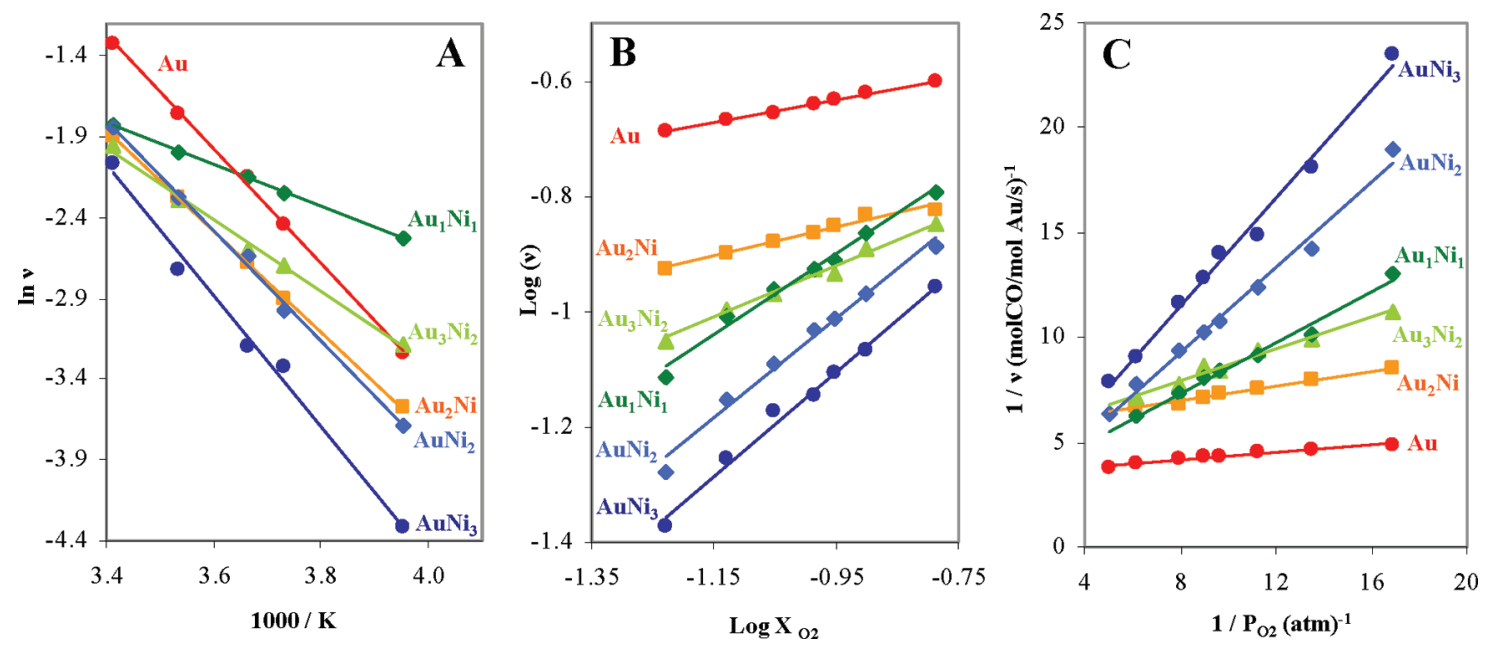

Figure 3. $\mathrm{CO}$ oxidation results for $\mathrm{Au}-\mathrm{Ni}$ catalysts; rates are in mol $\mathrm{CO} / \mathrm{mol} \mathrm{Au} / \mathrm{s}$ : (A) Arrhenius plots of the temperature dependence; (B) oxygen pressure dependence; and (C) double reciprocal plots for extracting kinetic characterization parameters.

there are no peaks attributable to surface $\mathrm{Ni}\left(\sim 2060 \mathrm{~cm}^{-1}\right)^{41,42}$ or $\mathrm{NiO}\left(\mathrm{ca} .2170 \mathrm{~cm}^{-1}\right){ }^{27}$ The absence of these peaks suggests that the NPs retain their Ni@Au core-shell structure after alkylthiol removal. This is also consistent with the large $\mathrm{Au}$ surface segregation energy in Au-based alloys, ${ }^{43}$ which provides a strong driving force for creating the $\mathrm{Au}$ shell. We also performed additional DFT calculations, which showed that Au was substantially more stable on the surface (vide infra). Although the IR data indicate that Au is predominately on the catalyst surface, the low metal loadings make it impossible to rule out the possibility that small amounts of surface $\mathrm{Ni}$ or $\mathrm{NiO}$ may also be present at levels below the detection limits.

CO Oxidation Catalysis. The activated NPs were evaluated as $\mathrm{CO}$ oxidation catalysts by using a differential single pass plug flow microreactor, as described in the Experimental Section and in our previous study, which reported an in-depth comparison between the pure Au catalyst here and a conventionally prepared test catalyst. ${ }^{33}$ Particle sizes (via TEM), XPS spectra, $\mathrm{CO}$ binding equilibrium constants (measured by infrared spectroscopy), ${ }^{44}$ and $\mathrm{CO}$ oxidation catalysis kinetics (apparent activation energies and $\mathrm{O}_{2}$ reaction orders) were all the same within very reasonable experimental errors for the MPC and the WGC catalysts. The only significant difference between the WGC and MPC catalysts is that the catalytic activity of the MPC catalyst is about $40 \%$ higher. Thus, there are no deleterious effects of using the thiol-stabilized precursor, and the MPC system is an appropriate model for traditionally prepared $\mathrm{Au}$ catalysts.

$\mathrm{CO}$ oxidation kinetics data (Arrhenius plots, $\mathrm{O}_{2}$ reaction orders, and double reciprocal plots) were all collected by using catalysts diluted 1250:1 with SiC. Catalyst masses and flow rates, and therefore space velocities, were adjusted so that conversions were always maintained between $1 \%$ and $2 \%$. These conditions have been shown to maintain the catalysts under kinetic control. ${ }^{33}$ These data are presented in Figure 3. The changes in the slopes of the lines fitted to the data in Figure 3 all show the NP Ni content has a dramatic effect on the kinetic parameters. These data are summarized in Figure 4, which plots the various kinetic parameters against the bulk catalyst $\mathrm{Ni}$ content determined by AA spectroscopy. Both apparent activation energy ( $E_{\text {app }}$, Figures $3 \mathrm{~A}$ and $\left.4 \mathrm{~A}\right)$ and the $\mathrm{O}_{2}$ reaction order (Figures 3B and 4A) show substantial changes as the Ni content increases above $30 \mathrm{~mol} \% \mathrm{Ni}$. The behavior of the kinetics
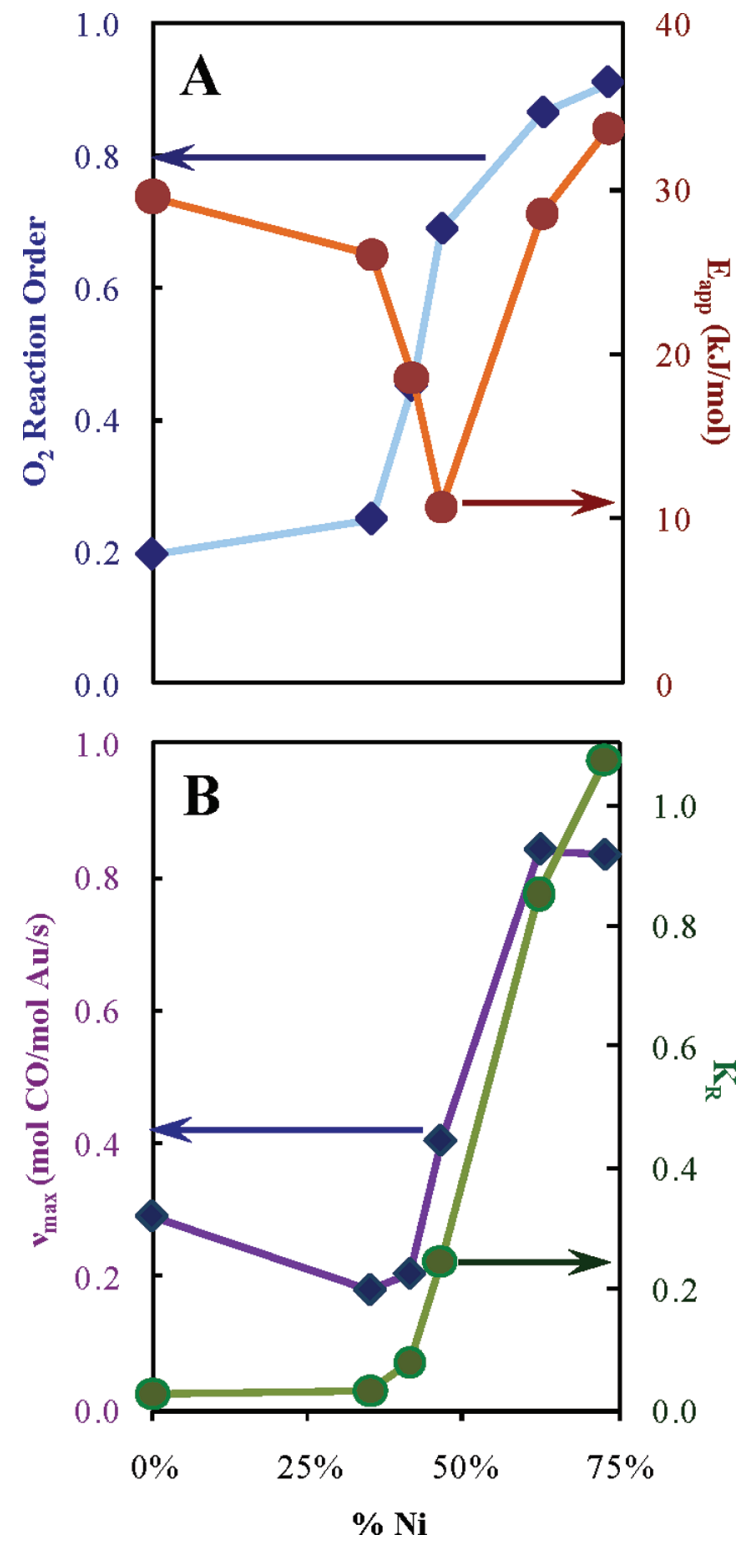

Figure 4. Changes in $\mathrm{CO}$ oxidation catalysis parameters: (A) $\mathrm{O}_{2}$ reaction order and apparent activation energy and (B) extracted kinetic parameters $v_{\max }$ and $K_{\mathrm{R}}$ as a function of catalyst Ni content. 
SCHEME 1

$$
\begin{aligned}
& \mathrm{Au}+\mathrm{CO} \stackrel{\text { fast }}{\rightleftarrows} \mathrm{Au}-\mathrm{CO} \\
& \mathrm{A}^{*}+\mathrm{O}_{2} \stackrel{\mathrm{k}_{1}}{\underset{\mathrm{k}_{-1}}{\longrightarrow}} \mathrm{A}^{*}-\mathrm{O}_{2} \\
& \mathrm{~A}^{*}-\mathrm{O}_{2}+\mathrm{Au}-\mathrm{CO} \stackrel{\mathrm{k}_{2}}{\longrightarrow} \mathrm{A}^{*}-\mathrm{O}+\mathrm{Au}+\mathrm{CO}_{2} \\
& \mathrm{~A}^{*}-\mathrm{O}+\mathrm{Au}-\mathrm{CO} \stackrel{\text { fast }}{\longrightarrow} \mathrm{A}^{*}+\mathrm{Au}+\mathrm{CO}_{2}
\end{aligned}
$$

parameters diverges above about $50 \mathrm{~mol} \% \mathrm{Ni}$, with $E_{\text {app }}$ going through a minimum for the $\mathrm{Au}_{1} \mathrm{Ni}_{1}$ catalyst. The oxygen dependence, on the other hand, shows a relatively steady trend toward increasing reaction orders with additional $\mathrm{Ni}$.

The magnitude of the changes in these kinetic parameters is remarkable, and indicates a substantial modification of $\mathrm{Au}$ reactivity. The changes in $E_{\text {app }}$ are somewhat difficult to interpret because they depend on intrinsic kinetic barriers, heats of adsorption, and relative surface coverages. However, the magnitude of changes observed here is exceptionally large, as $E_{\text {app }}$ for $\mathrm{Au}_{1} \mathrm{Ni}_{1}$ is $60 \%$ of the $E_{\text {app }}$ value for monometallic $\mathrm{Au}$. Unfortunately, activation energies reported in the literature vary enormously depending on reaction conditions (particularly conversions, which generally are not held constant), research group, and catalyst preparation method. ${ }^{45}$ It is therefore very difficult to look to the literature for meaningful comparisons. Under our reaction conditions, however, the MPC-based Au/ $\mathrm{TiO}_{2}$ catalyst had essentially the same activation energy as a traditionally prepared $\mathrm{Au} / \mathrm{TiO}_{2}$ catalyst (within $1 \mathrm{~kJ} / \mathrm{mol}$ ). Further, our measurements are all made at very low conversion $(1-2 \%)$ and the average error in the $E_{\text {app }}$ measurements is \pm 0.8 $\mathrm{kJ} / \mathrm{mol}$. This is strong evidence that the observed differences between the Ni-containing catalysts are real and substantial.

The changes in $\mathrm{O}_{2}$ reaction order with $\mathrm{Ni}$ incorporation are similarly dramatic when considered in light of the available literature. ${ }^{46}$ More directly, the Haruta and Davis groups, both of whom performed relatively low conversion studies similar to ours, report essentially the same $\mathrm{O}_{2}$ dependence as we observe for monometallic $\mathrm{Au}(0.2-0.25){ }^{47,48}$ Vannice's group indicated similar dependences for their catalysts, although they did not report specific values. ${ }^{49}$ The available $\mathrm{O}_{2}$ reaction orders for $\mathrm{Au}$ supported on transition metal oxides are also similar to or smaller than those for titania supports: $\mathrm{Co}_{3} \mathrm{O}_{4}(0.27),{ }^{47} \mathrm{Fe}_{2} \mathrm{O}_{3}$ (0.05), ${ }^{47}$ and $\mathrm{CeO}_{2}(0.18) .{ }^{50,51}$ Calla and Davis report a slightly higher value for $\mathrm{Au} / \mathrm{Al}_{2} \mathrm{O}_{3}(0.36)$, although this value is substantially impacted by the amount of water in the feed..$^{52}$ These studies are generally consistent, indicating that the oxygen reaction order for monometallic supported $\mathrm{Au}$ catalysts is $0.1-0.35$. Measured reaction orders can strongly depend on the pressure range; although these are not always reported, most groups work at or below atmospheric $\mathrm{O}_{2}$ pressure. With that in mind, the changes we observe by incorporating Ni into the NP synthesis $\left(\mathrm{O}_{2}\right.$ orders from 0.2 to 0.9$)$ are much larger than those reported in the literature, even for $\mathrm{Au}$ supported on several different transition metal oxides $(\mathrm{Ti}, \mathrm{Co}, \mathrm{Fe}){ }^{45}$

Oxygen pressure dependence data can also be interpreted in terms of a Michaelis-Menten type treatment. ${ }^{33}$ The primary advantage of this treatment is that it provides a means of extracting quantitative parameters that describe $\mathrm{O}_{2}$ reactivity for individual gold catalysts. A full derivation of this treatment has been published and can also be found in the Supporting Information. ${ }^{33}$ Briefly, a simple mechanism (Scheme 1), which has also been suggested by DFT calculations, ${ }^{53,54}$ is used to describe the reaction. Applying a typical kinetic derivation utilizing the steady-state approximation yields the following expression:

$$
\frac{1}{v_{\mathrm{rxn}}}=\frac{K_{\mathrm{R}}}{v_{\max }}\left(\frac{1}{P_{\mathrm{O}_{2}}}\right)+\frac{1}{v_{\max }}
$$

where

$$
v_{\max }=k_{2}[\mathrm{Au}-\mathrm{CO}][\mathrm{A} *]_{\mathrm{T}}
$$

and

$$
K_{\mathrm{R}}=\frac{k_{-1}+k_{2}[\mathrm{Au}-\mathrm{CO}]}{k_{1}}
$$

The $[\mathrm{Au}-\mathrm{CO}]$ term represents the surface concentration or coverage of $\mathrm{CO}^{55}$ and $\left[\mathrm{A}^{*}\right]_{\mathrm{T}}$ is the total number of active sites, which is assumed to be a subset of the total number of surface $\mathrm{Au}$ sites. $K_{\mathrm{R}}$ and $\nu_{\max }$ are descriptive kinetic parameters comparable to those employed in enzyme kinetics. ${ }^{56}$ Analogous to the Michaelis-Menten constant, $K_{\mathrm{R}}$ is a measure of the reactivity or instability of adsorbed $\mathrm{O}_{2}$. Similarly, $v_{\max }$ depends both on the intrinsic reaction barrier and the number of active sites, which is generally considered unknown for $\mathrm{CO}$ oxidation over $\mathrm{Au} / \mathrm{TiO}_{2}$ catalysts. This kinetic treatment has been previously published and has been shown to do a good job of describing kinetic data for $\mathrm{CO}$ oxidation over Au catalysts. By using this treatment, the MPC derived Au catalyst was shown to have essentially the same $K_{\mathrm{R}}$ value as a traditionally prepared $\mathrm{Au} / \mathrm{TiO}_{2}$ catalyst; the only difference between the two catalysts was in a slightly larger $\nu_{\max }$ value for the MPC catalyst, which was concluded to have about $40 \%$ more active sites. ${ }^{33}$

The double reciprocal plots predicted by eq 1 and shown in Figure $3 \mathrm{C}$ are linear, indicating that the kinetic data are well described by this treatment. The extracted kinetic parameters are plotted as a function of Ni content in Figure 4B (tabulated values are in the Supporting Information). Both parameters begin to change sharply as the mol \% Ni increases above $30 \%$ and continue to increase as the Ni content increases. The changes in $K_{\mathrm{R}}$ values are especially large, increasing by a factor of 40 from $\mathrm{Au}$ to $\mathrm{AuNi}_{3}$. The changes to $v_{\max }$, which increases by a factor of 3 , are smaller, suggesting that a smaller number of more active $\mathrm{Au}$ sites result from incorporating Ni into the NP synthesis.

Catalyst-to-catalyst reproducibility was evaluated by preparing and testing the $\mathrm{Au}_{1} \mathrm{Ni}_{1}$ catalyst three separate times. Relative standard deviations in $v_{\max }$ and $K_{\mathrm{R}}$ due to the synthesis and measurement reproducibility were $22 \%$ and $32 \%$, respectively. Note that the errors in kinetic testing (32\%) are larger than those in the synthetic reproducibility (22\%). Although these errors appear large, they arise from the double inverse treatment of the data. For the six runs used to evaluate reproducibility, the reaction order was $0.70 \pm 0.06$, which is a very reasonable error $(8.5 \%)$ given the literature on this reaction. Further, the errors in the extracted $K_{\mathrm{R}}$ values (ca. 30\%) are small relative to the changes in $K_{\mathrm{R}}(4000 \%)$. This confirms that the changes observed in the kinetic parameters result from modifying $\mathrm{Au}$ by incorporating different amounts of Ni into the NP synthesis rather than errors in the measurements or synthetic protocol. 


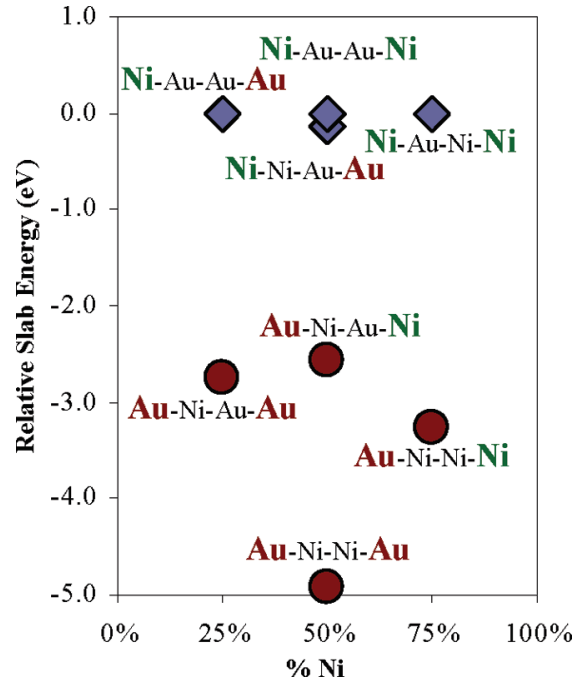

Figure 5. DFT calculation results on $\mathrm{Au}(111)$ slabs. Slab energies for $\mathrm{Au}-\mathrm{Ni}$ slabs; the colored atoms indicate the surface layers. Reported energies are relative to the slab with the maximum number of exposed $\mathrm{Ni}$ surfaces for that composition; energies are only comparable for slabs with the same overall composition.

To our knowledge, this is the first attempt to tune supported $\mathrm{Au}$ catalysts in a controllable fashion by incorporating a second metal into the NP. The kinetic data show that Ni incorporation has large effects on oxygen binding and activation, which is of widespread importance for the development of new Au-based oxidation catalysts. ${ }^{3,4}$ Increases in $K_{\mathrm{R}}$ and $v_{\max }$ indicate that incorporating Ni substantially increases oxygen reactivity at the $\mathrm{Au}$ active sites. The $v_{\max }$ value depends on both the intrinsic reactivity and the number of active sites, so its smaller overall increase suggests that higher amounts of Ni may reduce the total number of active sites.

DFT Calculations. Both computational ${ }^{57}$ and experimental ${ }^{58,59}$ studies have shown that incorporating Ni into Pt catalysts decreases the catalysts' ability to bind many adsorbates, making $\mathrm{Pt}-\mathrm{Ni}$ materials potential low-temperature hydrogenation catalysts. We therefore performed DFT calculations on the $\mathrm{Au}-\mathrm{Ni}$ system to gain further insight into these new catalysts and to understand how $\mathrm{Ni}$ might activate $\mathrm{Au}$ for $\mathrm{CO}$ oxidation. A combination of electronic and structural factors can influence bimetallic catalysts. For clarity, we refer to electronic influences as those arising from the nascent interactions between metals (e.g., modification of the d-band center, shifts in electron density due to electronegativity differences, etc.). Structural effects include geometry changes arising from lattice and atom size mismatches. These structural effects also include electronic differences arising from the introduction of under-coordinated surface atoms on roughened or higher index surfaces.

DFT calculations were performed on 4-layer $\mathrm{Au}(111)-\mathrm{Ni}$ slabs to investigate the relative stabilities of model structures and to evaluate potential electronic influences of $\mathrm{Ni}$ on $\mathrm{CO}$ and $\mathrm{O}$ adsorption. Figure 5 shows the relative stability of model $\mathrm{Au}-\mathrm{Ni}$ structures, based on the Au fcc lattice. The effects of lattice strain are well-known, with compressive strain generally inducing weaker substrate binding, due to stronger lateral metal-metal interactions, and expansive or tensile strain inducing stronger substrate binding, due to weaker lateral metal-metal interactions ${ }^{60}$ Therefore, the Au fcc lattice was used to isolate electronic effects and eliminate potential effects of lattice strain. The results presented in Figure 5 indicate that structures in which $\mathrm{Au}$ is on the surface of the slab are substantially more stable than when $\mathrm{Au}$ is in the center layers. This is not surprising given
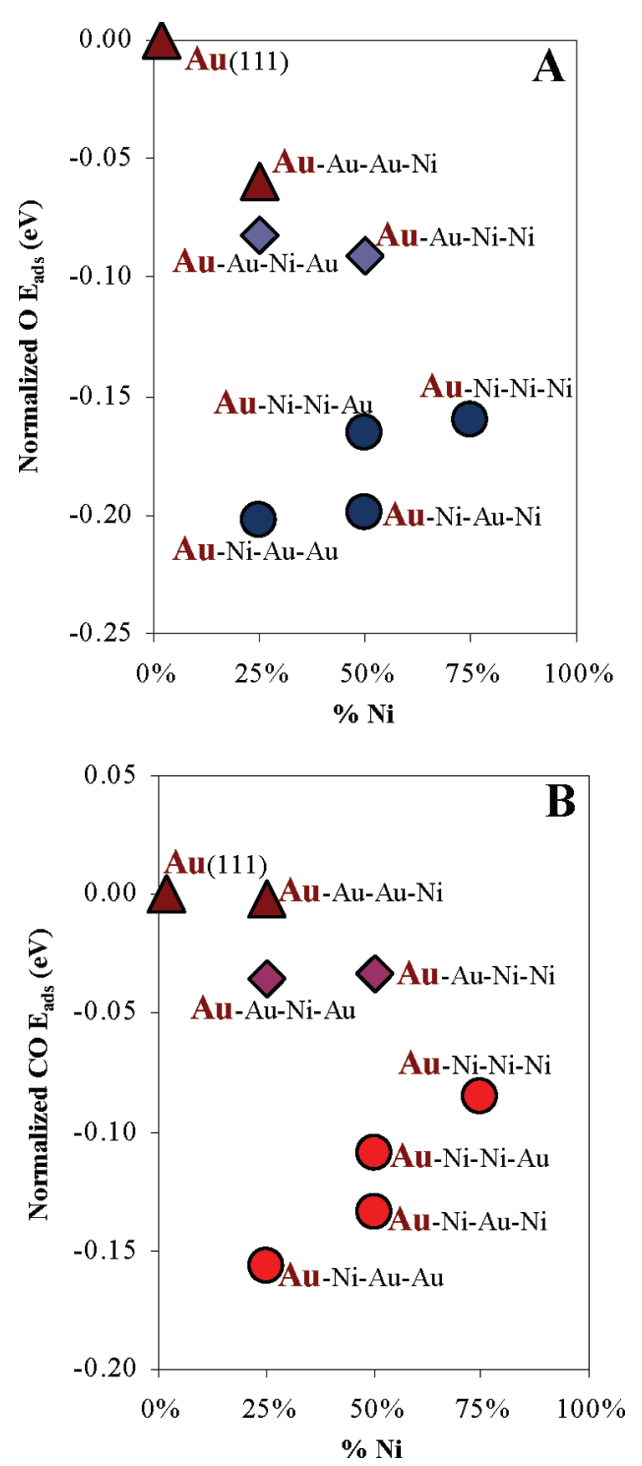

Figure 6. (A) Energies for $\mathrm{O}$ adsorption (3-fold hollow sites) on planar (111) slabs; the first (colored) layer indicates the adsorbing layer. (B) Energies for CO adsorption (atop sites) on planar (111) slabs. The first (colored) layer indicates the adsorbing layer $\left(\boldsymbol{\Lambda}=\mathrm{Au}_{\mathrm{ads}}-\mathrm{Au}-\mathrm{Au}-\mathrm{X}\right.$; $\left.\diamond=\mathrm{Au}_{\mathrm{ads}}-\mathrm{Au}-\mathrm{X}-\mathrm{X} ; \boldsymbol{\bullet}=\mathrm{Au}_{\mathrm{ads}}-\mathrm{X}-\mathrm{X}-\mathrm{X}\right)$.

the large surface segregation energies for Au-based alloys. ${ }^{43}$ Structures with $\mathrm{Ni}-\mathrm{Au}$ mixtures in the middle two layers had nearly the same overall energy as the pure layer slabs presented in Figure 5. Since mixing the middle two layers had only small effects on the overall slab stability, for clarity, those results are omitted here and can be found in the Supporting Information.

The $\mathrm{O}$ and $\mathrm{CO}$ adsorption energy calculations in Figure 6 give an indication of the potential nascent electronic influences for this bimetallic system. Atomic rather than molecular oxygen is used to speed the calculation, as $\mathrm{O}_{2}$ adsorption has been shown to scale linearly with $\mathrm{O}$ adsorption for several metals,${ }^{53}$ including a number of Au surfaces and clusters. ${ }^{53,61}$ The data for the $25 \%$ $\mathrm{Ni}$ slabs show that incorporating a subsurface monolayer of $\mathrm{Ni}$ into the $\mathrm{Au}$ lattice increases the $\mathrm{O}$ adsorption energy by about $0.2 \mathrm{eV}$. This effect diminishes as the Ni layer moves farther from the surface, indicating additional Au layers effectively screen the electronic influences. The $\mathrm{O}-\mathrm{Au}-\mathrm{Ni}-\mathrm{X}-\mathrm{X}$ data (Figure 6A in dark blue) show $\mathrm{O}$ adsorption is relatively insensitive to structures in the third and fourth layers, which is also consistent with the screening observed in the $25 \% \mathrm{Ni}$ data. 
The trends for $\mathrm{CO}$ adsorption energies are similar, although the maximum effect of $\mathrm{Ni}$ incorporation is slightly smaller at 0.15 $\mathrm{eV}$.

DFT calculations on model slabs are not ideal models for real catalysts. They do not include important factors such as particle size and composition distributions, support effects, the presence of numerous different high index planes or of more reactive corner and edge atoms, and the ability of supported NPs to relax in three dimensions to relieve lattice strain. These issues are extraordinarily expensive to deal with computationally; however, these effects are not necessarily well understood from an experimental standpoint, either. Fixing the bottom layer of the slab to the Au lattice admittedly provides an imperfect model for nanoparticle catalysts and ignores potential structural affects. However, this approach isolates the electronic effects originating from electron donation from these ill-defined and complicated potential structural effects. Although adsorption energies may not map directly onto NP catalyst, the trends that are unveiled are the important results. In this case, the DFT calculations suggest that introducing Ni into Au NPs results in an electronic modification of the Au surface that has stronger interactions with $\mathrm{O}$ and $\mathrm{CO}$.

Interpreting Kinetics and DFT Data. On the whole, the kinetics data indicate that adding Ni to Au NPs results in the catalysts with more reactive surface oxygen. At first glance, this appears to contradict the DFT calculations, which suggest that oxygen is bound more strongly when subsurface $\mathrm{Ni}$ is incorporated into Au slabs. To address this, it is important to carefully discuss the origins and meaning of $K_{\mathrm{R}}$. Once adsorbed onto the Au surface, the mechanism in Scheme 1 provides two reaction pathways for $\mathrm{O}_{2}$. It can either (a) desorb or (b) react with surface $\mathrm{CO}$, proceeding to form the $\mathrm{CO}_{2}$ product. $K_{\mathrm{R}}$ describes the total reactivity of adsorbed $\mathrm{O}_{2}$; it is the ratio of the sum of the rates for processes $\mathrm{a}$ and $\mathrm{b}$ to the rate of adsorption. Figure $4 \mathrm{~B}$ shows that $K_{\mathrm{R}}$ increases with the catalyst $\mathrm{Ni}$ content; therefore, the most straightforward interpretation of these data, with no additional assumptions, is that adsorbed $\mathrm{O}_{2}$ becomes more reactive as $\mathrm{Ni}$ is incorporated into the catalyst. This definition draws no conclusion regarding which pathway (desorption or reaction) is favored, only that the $\mathrm{O}_{2}$ is more reactive toward one or both of the pathways, relative to the rate constant for adsorption.

The DFT calculations suggest that incorporating Ni into the catalysts increases the $\mathrm{O}$ adsorption energy. Although perhaps not immediately obvious, this trend correlates well with the kinetics results, which indicate that $\mathrm{Ni}$ incorporation increases $\mathrm{O}_{2}$ reactivity. The explanation for this apparent contradiction is as follows. Atomic $\mathrm{O}$ adsorption studies are used because they scale linearly with $\mathrm{O}_{2}$ adsorption energies, yet are less expensive to calculate. ${ }^{53}$ DFT calculations have also shown that a number of Brønsted-Evans-Polanyi (BEP) relations, which are merely linear free energy relationships (LFERs), exist between adsorption energies and important transition states in a number of catalytic reactions. For $\mathrm{CO}$ oxidation catalysis, the transition state energy for $\mathrm{O}_{2}$ splitting to $2 \mathrm{O}$ scales linearly with $\mathrm{O}$ adsorption energy for several metals, including several $\mathrm{Au}$ surfaces and clusters. ${ }^{53,61}$ Similarly, the transition state energies for the reaction between adsorbed $\mathrm{CO}$ and adsorbed $\mathrm{O}_{2}$ or $\mathrm{O}$ scale linearly with the sum of the $\mathrm{O}$ and $\mathrm{CO}$ adsorption energies. ${ }^{53,61}$ So, the DFT results in Figure 6, which suggest that the electronic effects of incorporating $\mathrm{Ni}$ into $\mathrm{Au}$ slabs induces stronger $\mathrm{O}$ and $\mathrm{CO}$ binding, predict that these surfaces will show enhanced $\mathrm{CO}$ oxidation activity. This is entirely consistent with the kinetics measurements, which show that Ni incorporation increases the measured $K_{\mathrm{R}}$ values, which describe the overall reactivity of adsorbed $\mathrm{O}_{2}$.

It is also important to note that the $K_{\mathrm{R}}$ values are not an explicit binding constant. In the study that first offered the Michaelis-Menten treatment for $\mathrm{CO}$ oxidation over Au catalysts, we initially interpreted $K_{\mathrm{R}}$ in terms of an $\mathrm{O}_{2}$ binding constant by assuming that the reaction with $\mathrm{CO}$ was slow relative to simple $\mathrm{O}_{2}$ dissociation. The current data from the $\mathrm{Ni}-\mathrm{Au}$ catalysts suggest that this may not be a good assumption; rather, the $K_{\mathrm{R}}$ term may be dominated by the term originating from the forward reaction with $\mathrm{CO}$. This is perhaps more easily seen by expanding the Michaelis-Menten treatment. First, the equilibrium expression for $\mathrm{CO}$ binding can be used to describe the first step in the mechanism, which is assumed to be a rapidly established pre-equilibrium:

$$
K_{\mathrm{CO}}=\frac{[\mathrm{Au}-\mathrm{CO}]}{P_{\mathrm{CO}}[\mathrm{Au}]_{\mathrm{CO}}}
$$

This allows $K_{\mathrm{R}}$ and $v_{\max }$ to be expressed as:

$$
v_{\max }=k_{2} K_{\mathrm{CO}} P_{\mathrm{CO}}[\mathrm{Au}]_{\mathrm{CO}}\left[\mathrm{A}^{*}\right]_{\mathrm{T}}
$$

and

$$
K_{\mathrm{R}}=\frac{k_{-1}+k_{2} K_{\mathrm{CO}} P_{\mathrm{CO}}[\mathrm{Au}]_{\mathrm{CO}}}{k_{1}}
$$

or

$$
K_{\mathrm{R}}=\frac{1}{K_{\mathrm{O}_{2}}}+\frac{k_{2} K_{\mathrm{CO}} P_{\mathrm{CO}}[\mathrm{Au}]_{\mathrm{CO}}}{k_{1}}
$$

Where $[\mathrm{Au}]_{\mathrm{CO}}$ is the concentration of Au surface sites capable of binding $\mathrm{CO}$. For $\mathrm{Au} / \mathrm{TiO}_{2}$ catalysts, the number of $\mathrm{CO}$ binding sites has been shown to be less than the total number of surface sites. $^{44,62,63}$

$K_{\mathrm{R}}$ should be strictly interpreted in terms the total reactivity of adsorbed $\mathrm{O}_{2}$; this can only correspond to a maximum value for the $\mathrm{O}_{2}$ binding constant $\left(K_{\mathrm{R}}\right.$ is inversely related to the equilibrium binding constant). The $\mathrm{Ni}-\mathrm{Au}$ data show dramatic increases in $K_{\mathrm{R}}$ relative to pure $\mathrm{Au}$. One of two scenarios must then hold true, either (a) the first part of the $K_{\mathrm{R}}$ term dominates and $\mathrm{O}_{2}$ binding gets substantially weaker upon $\mathrm{Ni}$ incorporation or (b) $K_{\mathrm{R}}$ is dominated by the forward reaction with $\mathrm{CO}$.

The first scenario seems unlikely. $\mathrm{O}_{2}$ binding by $\mathrm{Au}$ is exceedingly weak; in fact, the only direct evaluation of the $\mathrm{O}_{2}$ binding constant by $\mathrm{Au}$ catalysts is our kinetic determination, ${ }^{33}$ which yields only a maximum value. It is difficult to imagine catalysts that bind oxygen even more weakly than pure $\mathrm{Au}$, and especially 40 times more weakly, being effective CO oxidation catalysts. The second scenario seems much more likely. On the basis of the DFT calculations, both the $k_{2}$ and $K_{\mathrm{CO}}$ portions of the second term in the $K_{\mathrm{R}}$ expression (eqs 6 and 7) would be expected to be affected by structural and electronic changes arising from Ni incorporation. The product of these two terms would amplify the effects of structural/electronic changes on the $K_{\mathrm{R}}$ term, and could reasonably give rise to a 40-fold increase in $K_{\mathrm{R}}$. Therefore, the data for the $\mathrm{Ni}-\mathrm{Au}$ catalysts are most consistent with $\mathrm{Ni}$ enhancing both $\mathrm{O}_{2}$ binding and reaction, with 


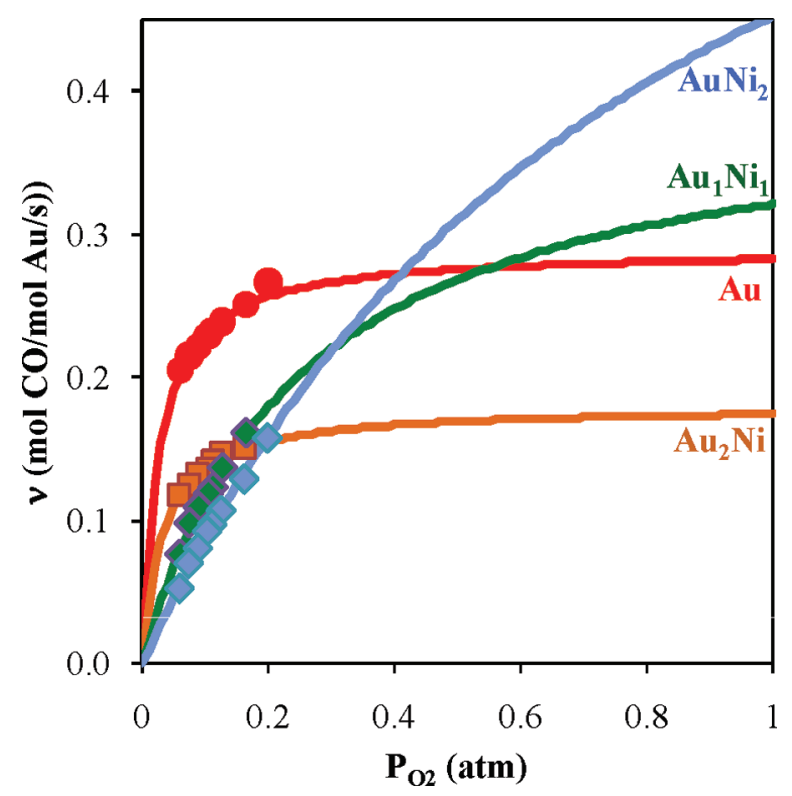

Figure 7. Oxygen saturation plots for $\mathrm{Ni}-\mathrm{Au}$ catalysts at $20^{\circ} \mathrm{C}$. Closed symbols are experimental data; fitted lines come from the $K_{\mathrm{R}}$ and $v_{\max }$ values determined with eq 1 .

the measurable $K_{\mathrm{R}}$ term being dominated by the reaction $\left(k_{2} K_{\mathrm{CO}} P_{\mathrm{CO}}[\mathrm{Au}]_{\mathrm{CO}}\right)$ term.

The $K_{\mathrm{R}}$ and $v_{\max }$ descriptors also originate from the $\mathrm{O}_{2}$ pressure dependence data, so it is useful to consider how these factors interrelate, and what they can tell us about how $\mathrm{Ni}$ modifies Au catalysts. This is often interpreted in terms of the oxygen reaction order, which originates from a slightly different mathematical treatment of the $\mathrm{O}_{2}$ pressure dependence data. Changes in the oxygen reaction order do not necessarily indicate a change in the reaction mechanism; however, they do provide important information regarding this key mechanistic step. In a simple sense, the experimental reaction order relates to where the catalyst operates along the kinetic oxygen saturation curve for a given pressure range. Catalysts with reaction orders near 0 operate near the kinetic saturation limit (i.e., where the $\mathrm{O}_{2}$ reaction proceeds as quickly as possible, not necessarily where the surface is saturated with $\mathrm{O}_{2}$ ). Catalysts with reaction orders near 1 operate "earlier" on the saturation curve, where oxygen binding/reaction is more sensitive to the oxygen pressure and reaction rates are readily enhanced by increasing the partial pressure of oxygen in the feed. In terms of catalyst characterization, the reaction order can also be interpreted as describing the shape of the saturation curve for a given catalyst, under the conditions of the catalytic reaction. Low reaction orders suggest a saturation curve compressed to lower pressures (i.e., saturation occurs at lower pressures), while higher reaction orders suggest a saturation curve that is elongated over a wider pressure range.

Full oxygen saturation curves can be readily generated from the $K_{\mathrm{R}}$ and $\nu_{\max }$ descriptors by rearranging and plotting eq 1 ; those plots are shown in Figure 7 (the $\mathrm{Au}_{2} \mathrm{Ni}_{3}$ and $\mathrm{AuNi}_{3}$ catalysts were omitted for clarity). The plots very clearly show how changes in the oxygen pressure dependence, and hence in $K_{\mathrm{R}}$ and $v_{\max }$, affect the bend of the saturation curve for the different catalysts. Not surprisingly, they indicate that catalyst performance depends substantially on the reaction conditions.

The oxygen saturation plots also provide some further insight into how Ni changes catalysis by Au. Of note is the change in $K_{\mathrm{R}}$ (40-fold increase) relative to $\nu_{\max }$ (3-fold increase). The primary difference between these two descriptors is that $v_{\max }$ includes a relative measure of the number of active sites present on the catalyst. Comparing the saturation curves for the Au and $\mathrm{Au}_{2} \mathrm{Ni}$ catalysts, it is clear that they behave similarly. Both are largely saturated in the range shown and the shapes of the curves are generally the same, arising from the similarities of the $K_{\mathrm{R}}$ values $(0.026$ and 0.032 , respectively). The only real difference between these two catalysts is that $\mathrm{Au}_{2} \mathrm{Ni}$ is approximately $40 \%$ less active than $\mathrm{Au} / \mathrm{TiO}_{2}$. This indicates that the two catalysts have roughly the same inherent ability to catalyze the reaction, but that $\mathrm{Au}_{2} \mathrm{Ni}$ has about $40 \%$ fewer active sites. As the $\mathrm{Ni}$ content of the catalyst increases, the modifications to the active site(s) become more substantial, evidenced by the changes in the shapes of the curves and higher saturation pressures for $\mathrm{Au}_{1} \mathrm{Ni}_{1}$ and $\mathrm{AuNi}_{2}$. This may also help to explain why the catalysts with greater $\mathrm{Ni}$ content do not have greater overall activities at lower pressures: although adding $\mathrm{Ni}$ results in active sites that can more easily bind and activate oxygen, it decreases the relative number of active sites.

Comments on $\mathrm{Ni}$. The nature and state of the $\mathrm{Ni}$ are important factors in understanding how $\mathrm{Ni}$ might be tuning catalysis by Au. We have attempted several XPS studies of these materials in order to determine the Ni oxidation state. Unfortunately, the metal loadings attainable through our current synthetic procedures are low enough that we have not been able to observe peaks attributable to Ni. Further, the Au peaks are also small and are too broad relative to the background noise to reliably evaluate any changes in Au core electron binding energies. We are currently working to develop synthetic procedures that will allow us to prepare larger amounts of catalysts with higher weight loadings in order to address this question more completely.

At the same time, placing the experimental data into the context of the calculations, the synthesis, and the available literature provides some guidance. First, the computational study indicates that the increased $\mathrm{O}_{2}$ binding observed in the kinetics experiments is consistent with reduced $\mathrm{Ni}^{0}$ being present near the active site. Second, a number of the synthetic procedures are designed to favor the preparation of reduced $\mathrm{Ni}$ species. The metal salts are treated with borohydride, which is a strong enough reducing agent to reduce $\mathrm{Ni}^{\mathrm{II}}$ to $\mathrm{Ni}^{0}{ }^{0}$. Additionally, $\mathrm{Au}$ preferentially segregates to the surface of $\mathrm{Ni}-\mathrm{Au}$ alloys ${ }^{43}$ and thiol stabilizers enhance this effect by binding Au more strongly than Ni. ${ }^{30} \mathrm{MPC}$ isolation and deposition are then carried out in the absence of $\mathrm{O}_{2}$ by using Schlenk techniques, and the supported MPCs are subsequently treated in flowing $\mathrm{H}_{2}$ at $300{ }^{\circ} \mathrm{C}$ for $16 \mathrm{~h}$ immediately prior to kinetic testing. Given these treatments and the mild reaction conditions, it is reasonable to conclude that reduced $\mathrm{Ni}$ species are possibly and even likely present.

Third, the infrared spectra of $\mathrm{CO}$ adsorbed to the catalysts show no peaks that can be assigned to either $\mathrm{Ni}^{0}$ or $\mathrm{Ni}$ oxide surface species. If $\mathrm{NiO}$ species are present, they must be so at levels below the detection limits of the $\mathrm{CO}$ adsorption experiment. Fourth, the changes we observe in the $\mathrm{O}_{2}$ reaction order for the highest $\mathrm{Ni}$ content catalysts are higher than those reported in the literature for several transition metal oxide supports. As discussed previously, reaction orders between 0.15 and 0.35 have been reported for Au supported on $\mathrm{Ti}, \mathrm{Co}$, and $\mathrm{Fe}$ oxides. The reaction orders of $0.7,0.85$, and 0.9 for $\mathrm{Au}_{1} \mathrm{Ni}_{1}, \mathrm{AuNi}_{2}$, and $\mathrm{AuNi}_{3}$, respectively, are much larger than the literature reports. This indicates that the data for the $\mathrm{Ni}-\mathrm{Au}$ catalysts are therefore not consistent with what one would expect for variances due to metal-support interactions. In other words, it appears that $\mathrm{Ni}$ incorporation into the NP synthesis results in a different $\mathrm{Ni}-\mathrm{Au}$ 
interaction that has a larger effect on the $\mathrm{CO}$ oxidation catalysis than one would expect based on support effects alone.

Admittedly, this is somewhat circumstantial evidence. Since XPS studies have been inconclusive, we cannot rule out the presence or possible role of Ni oxide in these catalysts, in spite of our reasonable efforts. Regardless of the ultimate cause of these effects, the data clearly show that incorporating $\mathrm{Ni}$ into the Au NP synthesis results in a previously unreported ability to tune the kinetics of $\mathrm{CO}$ oxidation catalysis. We look forward to future experiments using improved synthetic methods that will allow us to begin addressing questions regarding the origins of the unique catalytic properties of the $\mathrm{Ni}-\mathrm{Au}$ catalysts.

\section{Conclusions}

Using anchored dendrimers to prepare DENs and MPCs, we developed a synthesis for controllably incorporating $\mathrm{Ni}$ into supported Au NP catalysts. TEM indicated particles on the order of $2 \mathrm{~nm}$ and confirmed that $\mathrm{Ni}$ and $\mathrm{Au}$ were present in individual NPs. Kinetics studies showed that Ni has dramatic effects on $\mathrm{CO}$ oxidation catalysis by Au. These effects are substantially larger than previous reports for support effects on Au-based CO oxidation catalysts. Beyond large changes in the apparent activation energy, $\mathrm{Ni}$ incorporation appears to tune the oxygen reactivity, with increasing $\mathrm{Ni}$ contents resulting in greater $\mathrm{O}_{2}$ reaction orders and more reactive surface $\mathrm{O}_{2}$. Infrared spectroscopy of adsorbed $\mathrm{CO}$ showed only surface $\mathrm{Au}$; there was no evidence for the presence of surface $\mathrm{Ni}^{0}$ or $\mathrm{NiO}$ in the infrared spectrum. Complementary DFT calculations indicate that there is a strong driving force for segregating Au to the surface of $\mathrm{Ni}-\mathrm{Au}$ alloys, consistent with the absence of $\mathrm{Ni}-\mathrm{CO}$ peaks in the infrared spectrum. Further, $\mathrm{CO}$ and $\mathrm{O}$ adsorption energy calculations were also generally consistent with the increased oxygen reactivity observed in $\mathrm{CO}$ oxidation kinetics. Further analysis of the kinetics data indicated that, although $\mathrm{Ni}$ incorporation increased the reactivity of surface oxygen, it reduced the relative number of active sites on the catalyst. To our knowledge, this is the first example of controllably tuning the heterogeneous catalytic properties of Au by doping with another metal.

Acknowledgment. The authors gratefully acknowledge the Robert A. Welch Foundation (Grant nos. W-1552 and F-1529) and the U.S. National Science Foundation (Grant no. CHE0449549) for financial support of our work. The Kratos XPS was funded by the National Science Foundation under grant CHE-0618242. B.D.C. gratefully acknowledges the donors of the Petroleum Research Fund for a UFS grant to support his academic leave at the Center for Atomic-Scale Materials Design, which is supported by the Lundbeck Foundation. The authors also thank the Danish Center for Scientific Computing for computer time and Prof. Jens K. Nørskov, Dr. Frank AbildPederson, and Mr. Tao Jiang for their helpful discussions and guidance in performing DFT calculations.

Supporting Information Available: Additional TEM micrographs and DRIFTS spectra; catalyst composition and CO oxidation kinetics data; reproducibility data; rate law derivation; and detailed experimental section. This material is available free of charge via the Internet at http://pubs.acs.org.

\section{References and Notes}

(1) Bond, G. C.; Louis, C.; Thompson, D. T. Catalysis by Gold; Imperial College Press: London, UK, 2006; Vol. 6.

(2) Kung, M. C.; Davis, R. J.; Kung, H. H. J. Phys. Chem. C 2007, $111,11767$.
(3) Corma, A.; Garcia, H. Chem. Soc. Rev. 2008, 37, 2096.

(4) Hashmi, S. K.; Hutchings Graham, J. Angew. Chem., Int. Ed. Engl. 2006, $45,7896$.

(5) Comotti, M.; Li, W.-C.; Spliethoff, B.; Schueth, F. J. Am. Chem. Soc. 2006, 128, 917.

(6) Chen, M. S.; Goodman, D. W. Science (Washington, DC, U.S.) 2004, 306, 252.

(7) Stiehl, J. D.; Kim, T. S.; McClure, S. M.; Mullins, C. B. J. Am. Chem. Soc. 2004, 126, 13574.

(8) Matthey, D.; Wang, J. G.; Wendt, S.; Matthiesen, J.; Schaub, R.; Laegsgaard, E.; Hammer, B.; Besenbacher, F. Science (Washington, DC, U.S.) 2007, 315, 1692.

(9) Janssens, T. V. W.; Clausen, B. S.; Hvolbaek, B.; Falsig, H.; Christensen, C. H.; Bligaard, T.; Norskov, J. K. Top. Catal. 2007, 44, 15. (10) Catalysis by Metals and Alloys; Ponec, V., Bond, G. C., Eds.; Elsevier: Amsterdam, The Netherlands, 1995; Vol. 95.

(11) Kumar, D.; Chen, M. S.; Goodman, D. W. Catal. Today 2007, 123, 77.

(12) Mozer, T. S.; Dziuba, D. A.; Vieira, C. T. P.; Passos, F. B. J. Power Sources 2009, 187, 209.

(13) Liu, X.; Wang, A.; Wang, X.; Mou, C.-Y.; Zhang, T. Chem. Commun. (Cambridge, U.K.) 2008, 3187.

(14) Liu, X.; Wang, A.; Yang, X.; Zhang, T.; Mou, C.-Y.; Su, D.-S.; Li, J. Chem. Mater. 2009, 21, 410.

(15) Della Pina, C.; Falletta, E.; Rossi, M. J. Catal. 2008, 260, 384.

(16) Cardenas-Lizana, F.; Gomez-Quero, S.; Hugon, A.; Delannoy, L.; Louis, C.; Keane, M. A. J. Catal. 2009, 262, 235.

(17) Ferro, R.; Saccone, A.; Maccio, D.; Delfino, S. Gold Bull. 2003, $36,39$.

(18) Lang, H.; Maldonado, S.; Stevenson, K. J.; Chandler, B. D. J. Am. Chem. Soc. 2004, 126, 12949.

(19) Hoover, N. N.; Auten, B. J.; Chandler, B. D. J. Phys. Chem. B 2006, 110,8606 .

(20) Besenbacher, F.; Chorkendorff, I.; Clausen, B. S.; Hammer, B.; Molenbroek, A. M.; Norskov, J. K.; Stensgaard, I. Science 1998, 279, 1913. (21) Lahr, D. L.; Ceyer, S. T. J. Am. Chem. Soc. 2006, 128, 1800.

(22) Wang, G.-C.; Jiao, J.; Bu, X.-H. J. Phys. Chem. C 2007, 111, 12335.

(23) Bienzle, M.; Oishi, T.; Sommer, F.; Cmpds, J. A. J. Alloys Compd. 1995, 220, 182.

(24) Molenbroek, A. M.; Norskov, J. K.; Clausen, B. S. J. Phys. Chem. B 2001, 105, 5450 .

(25) Yuan, G.; Louis, C.; Delannoy, L.; Keane, M. A. J. Catal. 2007, $247,256$.

(26) Zhou, S.; Yin, H.; Schwartz, V.; Wu, Z.; Mullins, D.; Eichhorn, B.; Overbury, S. H.; Dai, S. ChemPhysChem 2008, 9, 2475.

(27) Tkachenko, O. P.; Kustov, L. M.; Nikolaev, S. A.; Smirnov, V. V.; Klementiev, K. V.; Naumkin, A. V.; Volkov, I. O.; Vasil'kov, A. Y.; Murzin,

D. Y. Top. Catal. 2009, 52, 344.

(28) Luo, J.; Maye, M. M.; Petkov, V.; Kariuki, N. N.; Wang, L.; Njoki, P.; Mott, D.; Lin, Y.; Zhong, C.-J. Chem. Mater. 2005, 17, 3086.

(29) Hills, C. W.; Mack, N. H.; Nuzzo, R. G. J. Phys. Chem. B 2003, 107, 2626.

(30) Auten, B. J.; Hahn, B. P.; Vijayaraghavan, G.; Stevenson, K. J.; Chandler, B. D. J. Phys. Chem. C 2008, 112, 5365.

(31) Chen, D.; Li, J.; Shi, C.; Du, X.; Zhao, N.; Sheng, J.; Liu, S. Chem. Mater. 2007, 19, 3399.

(32) Liu, X.; Madix, R. J.; Friend, C. M. Chem. Soc. Rev. 2008, 37, 2243.

(33) Long, C. G.; Gilbertson, J. D.; Vijayaraghavan, G.; Stevenson, K. J.; Pursell, C. J.; Chandler, B. D. J. Am. Chem. Soc. 2008, 130, 10103.

(34) Zheng, N.; Stucky, G. D. J. Am. Chem. Soc. 2006, 128, 14278.

(35) Lang, H.; May, R. A.; Iversen, B. L.; Chandler, B. D. J. Am. Chem. Soc. 2003, 125, 14832.

(36) Hammer, B.; Hansen, L. B.; Nørskov, J. K. Phys. Rev. B 1999, 59, 7413.

(37) Nørskov, J. K.; Rossmeisl, J.; Logadottir, A.; Lindqvist, L.; Kitchin, J. R.; Bligaard, T.; Jonsson, H. J. Phys. Chem. B 2004, 108, 17886.

(38) Kurth, S.; Perdew, J. P.; Blaha, P. Int. J. Quantum Chem. 1999, 75,889 .

(39) Gilbertson, J. G.; Vijayaraghavan, G.; Stevenson, K. J.; Chandler, B. D. Langmuir 2007, 23, 11239.

(40) Ye, H.; Crooks, R. M. J. Am. Chem. Soc. 2007, 129, 3627.

(41) Yoshinobu, J.; Takagi, N.; Kawai, M. Phys. Rev. B: Condens. Matter Mater. Phys. 1994, 49, 16670.

(42) De Bokx, P. K.; Bonne, R. L. C.; Geus, J. W. Appl. Catal. 1987, 30,33 .

(43) Ruban, A. V.; Skriver, H. L.; Norskov, J. K. Phys. Rev. B: Condens. Matter Mater. Phys. 1999, 59, 15990.

(44) Hartshorn, H.; Pursell, C. J.; Chandler, B. D. J. Phys. Chem. C 2009, 113,10718 .

(45) Aguilar-Guerrero, V.; Gates, B. C. Catal. Lett. 2009, 130, 108.

(46) Although many research groups have employed CO oxidation as a test reaction, relatively few have reported reaction oders. For a complete 
review of the available kinetics studies, see Aguillar-Guerrero and Gates' review: Catal. Lett. 2009, 130, 108.

(47) Haruta, M.; Tsubota, S.; Kobayashi, T.; Kageyama, H.; Genet, M.; Delmon, B. J. Catal. 1993, 144, 175.

(48) Calla, J. T.; Davis, R. J. J. Catal. 2006, 241, 407.

(49) Lin, S. D.; Bollinger, M.; Vannice, M. A. Catal. Lett. 1993, 17, 245.

(50) Aguilar-Guerrero, V.; Gates, B. C. Chem. Commun. 2007, 3210

(51) Aguilar-Guerrero, V.; Gates, B. C. J. Catal. 2008, 260, 351.

(52) Calla, J. T.; Davis, R. J. Ind. Eng. Chem. Res. 2005, 44, 5403.

(53) Falsig, H.; Hvolboek, B.; Kristensen, I. S.; Jiang, T.; Bligaard, T. Christensen, C. H.; Norskov, J. K. Angew. Chem., Int. Ed. 2008, 47, 4835.

(54) Nørskov and co-workers recently proposed a similar mechanism based on DFT calculation. The primary difference between Scheme 1 and the DFT results is that Scheme 1 assumes that the reaction between surface $\mathrm{O}$ atoms and adsorbed $\mathrm{CO}$ (the last step in the scheme) is fast. The DFT study found this last reaction step to be fast for Au catalysts and further found that direct reaction between surface bound $\mathrm{O}_{2}$ and adsorbed $\mathrm{CO}$ was required to accurately describe Au catalysts.

(55) The surface coverage of $\mathrm{CO}$ is treated as a constant during the reaction, based on the independence of the reaction rate on $\mathrm{CO}$ pressure (reaction order $=0$ ).
(56) Our first paper deriving and employing the Michaelis-Menten treatment used $K_{\mathrm{R}}$ to describe $\mathrm{O}_{2}$ reactivity. On the basis of various feedback, we have changed the name of the constant so that it is not confused with a constant designed to describe inhibition.

(57) Kitchin, J. R.; Norskov, J. K.; Barteau, M. A.; Chen, J. G. J. Chem. Phys. 2004, 120, 10240.

(58) Murillo, L. E.; Goda, A. M.; Chen, J. G. J. Am. Chem. Soc. 2007, 129, 7101 .

(59) Menning, C. A.; Hwu, H. H.; Chen, J. G. J. Phys. Chem. B 2006, 110, 15471.

(60) Mavrikakis, M.; Hammer, B.; Norskov, J. K. Phys. Rev. Lett. 1998, $81,2819$.

(61) Jiang, T.; Mowbray, D. J.; Dobrin, S.; Falsig, H.; Hvolbaek, B.; Bligaard, T.; Norskov, J. K. J. Phys. Chem. C 2009, 113, 10548.

(62) Oxford, S. M.; Henao, J. D.; Yang, J. H.; Kung, M. C.; Kung, H. H. Appl. Catal., A 2008, 339, 180.

(63) Menegazzo, F.; Manzoli, M.; Chiorino, A.; Boccuzzi, F.; Tabakova, T.; Signoretto, M.; Pinna, F.; Pernicone, N. J. Catal. 2006, 237, 431.

(64) Latimer, W. M. Oxidation Potentials, 2nd ed.; Prentice-Hall, Inc: New York, 1952.

JP101845D 